\title{
Is Postoperative Albumin Level Related with Surgical Site Infection?
}

\author{
Kyungtae CHO, M.D. ${ }^{1}$, Sung Woo CHO, M.D., Ph.D. ${ }^{1}$, Sangchul YUN, M.D., Ph.D. ${ }^{1}$, \\ Suyeon Park, M.S. ${ }^{2}$ \\ Departments of ${ }^{1}$ Surgery and ${ }^{2}$ Biostatistics, Soonchunhyang University Seoul Hospital, Seoul, Korea
}

\begin{abstract}
Purpose: Surgical site infection (SSI) is a hospital-acquired infection (HAI) associated with increased mortality, length of hospital stay, and cost of hospitalization. The aim of this study was to identify the value of albumin as an indicator of the nutritional status, postoperative C-reactive protein (CRP), and white blood cell (WBC) levels in predicting an outbreak of SSI and SSI-related epidemiology after colorectal surgery and identifying the risk factors for SSI.

Materials and Methods: A total of 198 patients, who underwent colorectal surgery from September 1, 2015 to December 31, 2016, were included in the study. The patient identity, operation characteristics, and SSI data were analyzed retrospectively by a chart review and national SSI reporting sheet. The relationship of the SSI and clinical data was analyzed statistically, and the SSI detection time and post-operative inflammatory laboratory findings were analyzed individually using cumulative incidence analysis and cause-specific hazard model.

Results: The incidence of SSI post colorectal surgery was 15.7\% (31 out of 198 cases). Chronic renal failure (CRF), open surgery, long operation time, and stoma were identified as significant risk factors for SSI using univariate analysis. The CRF, long operation time, and stoma were significant risk factors according to multivariate analysis. The decrease in albumin on post-operative day (POD)\#3 and CRP elevation on POD\#4 were related to the early detection of SSI. Conclusion: The actual incidence of SSI might be higher than expected, particularly in cases where patients have several clinical and operative factors. In addition, the albumin level and multiple postoperative inflammation tests can be employed as an early predictors of SSI. (Surg Metab Nutr 2018;9:59-67)
\end{abstract}

Key Words: Surgical site infection, Colorectal surgery, Risk factors

\section{INTRODUCTION}

Hospital-acquired infection (HAI) is one of the biggest problems in recent medicine and surgical site infection (SSI) is the most common course of HAI. SSI occurs in $2 \sim 5 \%$ operations in the United States.[1] SSI is associated with increase in mortality, length of hospital stay and medical cost. [2-4] It is well known that SSI incidence is high after colorectal surgery, however its frequency of occurrence may not be accurate.[5]

In Korea, SSI has been reported intermittently and indirectly during the process of investigating HAI, and ac- curacy of these reports was considered doubtful as the reported incidence rate ranged from 2.0 to $9.7 \%$.66] In 2006, the Korean Nosocomial Infections Surveillance System (KONIS) was established to survey incidences of SSI across the nation. Many hospitals voluntarily participated in this surveillance system. This system employed KONIS Web-based Report and Analysis Program.[7-9] For a more effective surveillance of SSI, Korean Surgical Site Infection Surveillance (KOSSIS) program was developed in 2014. This system focused on SSI among nosocomial infections. One prospective multicenter study employed the KOSSIS program to evaluate SSI rates and identify risk

Received October 5, 2018. Accepted October 26, 2018.

Correspondence to: Sung Woo CHO, Department of Surgery, Soonchunhyang University Seoul Hospital, 59 Daesagwan-ro, Yongsan-gu, Seoul 04401, Korea

Tel: +82-2-709-9240, Fax: +82-2-749-0499, E-mail: orsay@schmc.ac.kr

(c) This is an open access article distributed under the terms of the Creative Commons Attribution Non-Commercial License (http://creativecommons.org/licenses/by-nc/4.0) which permits unrestricted non-commercial use, distribution, and reproduction in any medium, provided the original work is properly cited. 
factors for SSI. A total of 197 colon surgeries were included in the study. The incidence of SSI after colon surgery was reported as $10.15 \%$.[10]

The main purpose of this study is to confirm the effect of postoperative albumin levels which is commonly used as an indicator of the nutritional status of patient on development of SSI. Furthermore, this study aims to identify the value of postoperative c-reactive protein (CRP) and WBC levels in predicting outbreak of SSI after colorectal surgery in patients, who were rigorously examined and reported as per the standard survey process of KOSSIS. The study also aims to identify other clinical factors related to SSI after colorectal surgery.

\section{MATERIALS AND METHODS}

\section{Patient characteristics}

A total of 198 patients who underwent colorectal surgery between Sep. 1. 2015 and Dec. 31. 2016 were included in the study. Patient characteristics are reported in Table 1. There was no difference in sex ratio. The proportion of overweight patients with body mass index (BMI) $\geq 25$ was $29 \%$. Approximately $14 \%$ of patients were in American society of anesthesiologists (ASA) score 3 to 4. Compared with patients with hypertension or diabetes, the number of patients with $\mathrm{CRF}$ and chronic respiratory disease was relatively small (10 and 5, respectively).

\section{Study design}

The primary end-point of the study was to identify epidemiology of clinical variables associated with SSI and the secondary end-point was to identify postoperative albumin, CRP and WBC levels as predictors of SSI after colorectal surgery.

Patient and operation characteristics were identified by review of patient charts. Patient characteristics included age, sex, BMI, ASA score, and medical conditions including hypertension, diabetes, chronic renal failure, and pulmonary respiratory disease. Operation characteristics included type and method of operation, operation time, elective or non-elective operation and formation of stoma
(Table 2). Postoperative albumin, WBC and CRP levels were recorded every day starting on Postoperative day 1 (POD\#1) till day 5 (POD\#5). Laboratory test was not performed daily for some patients as some surgeons do not prefer daily testing.

SSI was confirmed by the operating surgeons as per definition of SSI and its classification by KOSSIS. Data from each patient with SSI was recorded in a clinical reporting sheet and included in the KOSSIS reporting system. In order to diagnose SSI post patient discharge, all patients who underwent colorectal surgery were evaluated for SSI during their clinic visit by surgeons. If SSI was found during these office visit, clinicians recorded the findings in patient charts.

First, the correlation between SSI and various clinical factors was statistically analyzed.

On the other hand, patients with SSI were divided into two groups, 'early SSI (ESSI; less than 7 days)' and 'late SSI (LSSI; 7 and more than 7 days)' based on the time the medical staff detected the infection. Correlation between ESSI/LSSI and clinical findings was analyzed.

\begin{tabular}{|c|c|}
\hline Variable & Number (\%) \\
\hline \multicolumn{2}{|l|}{ Sex } \\
\hline Male & $100(50.51)$ \\
\hline Female & $98(49.49)$ \\
\hline \multicolumn{2}{|l|}{ Age $(y r)$} \\
\hline$<65$ & 97 (48.99) \\
\hline$\geq 65$ & $101(51.01)$ \\
\hline \multicolumn{2}{|c|}{ Body mass index (BMl; $\left.\mathrm{kg} / \mathrm{m}^{2}\right)$} \\
\hline$<25$ & $135(68.18)$ \\
\hline$\geq 25$ & $59(29.80)$ \\
\hline \multicolumn{2}{|c|}{$\begin{array}{l}\text { American Society of Anesthesiologists } \\
\text { (ASA) physical status score }(1 \sim 5)\end{array}$} \\
\hline 1 or 2 & $170(85.86)$ \\
\hline 3 or 4 & $28(14.14)$ \\
\hline \multicolumn{2}{|l|}{ Hypertension } \\
\hline None & $111(56.06)$ \\
\hline Yes & $86(43.43)$ \\
\hline \multicolumn{2}{|l|}{ Diabetes mellitus } \\
\hline None & $158(79.80)$ \\
\hline Yes & $39(19.70)$ \\
\hline \multicolumn{2}{|l|}{ Chronic renal failure } \\
\hline None & $187(94.44)$ \\
\hline Yes & $10(05.05)$ \\
\hline \multicolumn{2}{|c|}{ Chronic respiratory disease } \\
\hline None & $192(96.97)$ \\
\hline Yes & $5(02.53)$ \\
\hline
\end{tabular}


This study was approved by Institutional Review Board of Soonchunhyang University Seoul Hospital (IRB No.2018-06-002). Because this was a retrospective study with minimal risk to patients, the Internal Review Board, Soonchunhyang University Seoul Hospital, exempted it

\begin{tabular}{l|c|}
\hline Table 2. Operative characteristics & \\
\hline \multicolumn{1}{|c}{ Variable } & Numbers $(\%)$ \\
\hline Laparoscopic/open surgery & \\
Lapa & $126(63.6)$ \\
Open & $72(36.4)$ \\
Elective/emergent & \\
Elec & $136(68.7)$ \\
Emer & $61(30.8)$ \\
Operative time (minutes) & \\
$<240$ & $100(50.5)$ \\
$\geq 240$ & $98(49.5)$ \\
Stoma creation & $173(87.4)$ \\
None & $25(12.6)$ \\
Yes & \\
Operation types & $36(18.2)$ \\
(Extended) Right hemicolectomy & $5(2.5)$ \\
Transverse colectomy & $6(3.0)$ \\
Left hemicolectomy & $37(18.7)$ \\
Anterior resection & $22(11.1)$ \\
Low anterior resection & $5(2.5)$ \\
Mile's operation & $13(6.6)$ \\
Hartmann's operation & $9(4.2)$ \\
Ileostomy reversal & $3(1.5)$ \\
Hartmann's reversal & $27(13.6)$ \\
Ileocecectomy & $36(18.2)$ \\
etc. & \\
\hline &
\end{tabular}

from obtaining informed consent from the patients whose records were included in the study.

\section{Study analysis}

In this study, we first tried to analyze the correlation between infection and various clinical features using the Chi-square test and then an in-depth analyzing was performed for the correlation between epidemiologic data and laboratory findings of two groups with a competing risk regression model. We employed two statistical analysis methodologies to identify the risk factors. Cut off points for continuous variables including postoperative serum albumin, CRP and WBC levels were calculated using Youden index (Table 3) and all blood lab levels were coded into binary variables based on it being higher or lower than the pre-determined reference point. First, $\mathrm{cu}^{-}$ mulative incidence analysis was performed by using cause-specific cumulative incidence function. Cumulative incidence was estimated for different causes of failure in each groups (Albumin, WBC or CRP events) and P-value was calculated by comparison for each factor across groups. Cumulative incidences of ESSI and LSSI were calculated individually. A Second, cause specific hazard model employed was based upon an inverse probability censoring weighting (IPCW) method. In the univariate

Table 3. Cut off table of Albumin, C-reactive protein (CRP) and White blood cell count (WBC) by Youden index

\begin{tabular}{|c|c|c|c|c|c|c|c|c|c|c|c|}
\hline & Criteria & Sensitivity & $95 \% \mathrm{Cl}^{\star}$ & Specificity & $95 \% \mathrm{Cl}$ & $\mathrm{PPV}^{\dagger}$ & $95 \% \mathrm{Cl}$ & $\mathrm{NPV}^{\ddagger}$ & $95 \% \mathrm{Cl}$ & $A U C^{\S}$ & $95 \% \mathrm{Cl}$ \\
\hline \multicolumn{12}{|c|}{ Albumin (g/dL) } \\
\hline POD 1 & $\leq 3.050$ & 516 & $0.334 \sim 0.694$ & 0.629 & $0.550 \sim 0.701$ & 0.205 & $0.125 \sim 0.315$ & 0.875 & $0.800 \sim 0.926$ & 0.549 & $0.429 \sim 0.669$ \\
\hline POD 2 & $\leq 3.35$ & 78 & $0.485 \sim 0.827$ & 0.467 & $0.390 \sim 0.546$ & 0.190 & $.125 \sim 0.280$ & 0.886 & $0.797 \sim 0.941$ & 0.496 & $0.387 \sim 0.606$ \\
\hline POD 3 & $\leq 3.95$ & 0.968 & $0.815 \sim 0.998$ & 0.178 & $0.126 \sim 0.248$ & 0.180 & $0.127 \sim 0.248$ & 0.968 & $0.815 \sim 0.998$ & 0.493 & $0.379 \sim 0.608$ \\
\hline POD 4 & 2.85 & 194 & $0.081 \sim 0.380$ & 0.886 & $0.826 \sim 0.928$ & 0.24 & $0.102 \sim 0.455$ & 0.855 & $0.792 \sim 0.903$ & 0.555 & $0.404 \sim 0.707$ \\
\hline POD 5 & .05 & & $0.251 \sim 0.607$ & & $0.668 \sim 0.806$ & 0.232 & $0.134 \sim 0.367$ & 0.873 & $0.805 \sim 0.921$ & 0.607 & $0.490 \sim 0.725$ \\
\hline \multicolumn{12}{|c|}{ CRP (mg/L) } \\
\hline POD 1 & $\geq$ & & $0.585 \sim 0.897$ & 0.497 & 75 & & & & 0.8 & 0.643 & 0.55 \\
\hline POD 2 & $\geq 10.79$ & 19 & $0.251 \sim 0.607$ & 55 & $0.681 \sim$ & 0.241 & $0.139 \sim$ & 0.875 & $0.807 \sim 0.922$ & 0.610 & $0.490 \sim 0.730$ \\
\hline POD 3 & $\geq 6.87$ & 0.645 & $0.454 \sim 0.802$ & 0.653 & $0.575 \sim 0.724$ & 0.256 & $0.167 \sim 0.37$ & 0.908 & $0.838 \sim 0.951$ & 0.659 & $0.551 \sim 0.767$ \\
\hline POD 4 & & & & & $0.854 \sim 0.947$ & & $0.196 \sim 0.592$ & & $0.813 \sim 0.917$ & 0.659 & $0.514 \sim 0.804$ \\
\hline POD 5 & $\geq 4.6$ & 52 & $0.278 \sim 0.637$ & 19 & $0.643 \sim 0.784$ & 0. & 0.135 & 76 & -0.924 & 0.637 & $0.520 \sim 0.754$ \\
\hline \multicolumn{12}{|c|}{ WBC $(/ \mu \mathrm{L})$} \\
\hline POD 1 & $\geq 12,750$ & & 607 & & $0.544 \sim$ & 0.171 & דות & & $t \sim 0.908$ & 0.544 & $0.425 \sim 0.663$ \\
\hline POD 2 & $\geq 9,650$ & 0.387 & $0.224 \sim 0.577$ & 0.713 & $0.637 \sim 0.779$ & 0.2 & $0.112 \sim 0.327$ & 0.862 & $0.791 \sim 0.913$ & 0.563 & $0.428 \sim 0.697$ \\
\hline POD 3 & $\geq 9,050$ & 0.419 & $0.251 \sim 0.607$ & 0.749 & $0.674 \sim 0.811$ & 0.237 & $0.137 \sim 0.373$ & 0.874 & $0.806 \sim 0.922$ & 0.561 & $0.440 \sim 0.682$ \\
\hline POD 4 & $\geq 8,500$ & & $0.198 \sim 0.546$ & 0.832 & $0.765 \sim 0.884$ & 0.282 & $0.156 \sim 0.451$ & 0.874 & $0.810 \sim 0.92$ & 0.601 & $0.455 \sim 0.746$ \\
\hline POD 5 & $\geq 7,350$ & 0.484 & $0.306 \sim 0.666$ & 0.713 & $0.637 \sim 0.779$ & 0.238 & $0.144 \sim 0.365$ & 0.881 & $0.812 \sim 0.929$ & 0.595 & $0.485 \sim 0.706$ \\
\hline
\end{tabular}

${ }^{\star} \mathrm{Cl}=$ Cumulative Index; ${ }^{\dagger} \mathrm{PPV}=$ Positive Predictive Value; ${ }^{\dagger} \mathrm{NPV}=$ Negative Predictive Value; ${ }^{\S}$ AUC $=$ Area under the ROC curve. 
analysis, a candidate risk factor with $\mathrm{P}$-value of less than 0.2 was employed, and backward variable selection was performed using a P-value of 0.05 in multiple analysis. $\mathrm{R}$ version 3.1.2 was employed for all statistical analysis (using 'cmprsk' and 'crrstep' packages). All statistical analyses were performed using SPSS, version 14.0.

\section{RESULTS}

The incidence of SSI after colorectal surgery in the current study was $15.7 \%$ (31 of 198 cases).

Based on univariate analysis, CRF (OR 4.0, 95\% CI, $1.046 \sim 14.926$ ), open surgery (OR 2.5, 95\% CI, $1.136 \sim$
5.381), operation time exceeding 240 minutes (OR 3.4, 95\% CI, 1.492 8.337) and stoma formation (OR 4.8, 95\% CI, $1.921 \sim 12.122$ ) are potential risk factors for occurrence of SSI post colorectal surgery (Table 4).

And then multivariate analysis was performed with these significant related factors in univariate analysis. Chronic renal failure (OR 4.0, 95\% CI, 1.046 14.926), longer operation time (OR 3.8, 95\% CI, 1.534 9.167) and stoma formation (OR 5.2, 95\% CI, 1.977 13.735) were determined to be statistically significant risk factors.

In-depth analysis of statistical relationship between epidemiologic factors and inflammatory lab tests for the ESSI/LSSI, from POD \#3, there is a tendency for cumu-

Table 4. Univariate analysis of risk factors for surgical site infection

\begin{tabular}{|c|c|c|c|c|c|c|}
\hline \multirow{2}{*}{ Variable } & \multicolumn{2}{|c|}{ SSI (\%) } & \multirow{2}{*}{ OR } & \multicolumn{2}{|c|}{$95 \% \mathrm{Cl}$} & \multirow{2}{*}{ P-value } \\
\hline & Yes & None & & Upper & Lower & \\
\hline \multicolumn{7}{|l|}{ Sex } \\
\hline Male & $16(51.6)$ & $84(50.3)$ & Ref. & & & \\
\hline Female & $15(48.4)$ & $83(49.7)$ & 1.054 & 0.489 & 2.269 & 0.893 \\
\hline \multicolumn{7}{|l|}{ Age (yr) } \\
\hline$<65$ & $15(48.4)$ & $82(49.1)$ & Ref. & & & \\
\hline$\geq 65$ & $16(51.6)$ & $85(50.9)$ & 1.029 & 0.478 & 2.216 & 0.942 \\
\hline \multicolumn{7}{|l|}{ BMI $\left(\mathrm{kg} / \mathrm{m}^{2}\right)$} \\
\hline$<25$ & $22(73.3)$ & $113(68.9)$ & Ref. & & & \\
\hline$\geq 25$ & $8(26.7)$ & $51(31.1)$ & 0.806 & 0.336 & 1.931 & 0.628 \\
\hline \multicolumn{7}{|l|}{ ASA score $(1 \sim 5)$} \\
\hline 1 or 2 & $26(83.9)$ & $144(86.2)$ & Ref. & & & \\
\hline 3 or 4 & $5(16.1)$ & $23(13.8)$ & 1.204 & 0.420 & 3.453 & 0.730 \\
\hline \multicolumn{7}{|c|}{ Lapascopic/Open surgery } \\
\hline Lapa & $14(45.2)$ & $112(67.1)$ & Ref. & & & \\
\hline Open & $17(54.8)$ & $55(32.9)$ & 2.473 & 1.136 & 5.381 & 0.022 \\
\hline \multicolumn{7}{|c|}{ Elective/Emergency operation } \\
\hline Elect & $21(67.7)$ & $115(69.3)$ & Ref. & & & \\
\hline Emer & $10(32.3)$ & $51(30.7)$ & 1.074 & 0.472 & 2.433 & 0.865 \\
\hline \multicolumn{7}{|l|}{ Operative time (min) } \\
\hline$<240$ & $8(25.8)$ & $92(55.1)$ & Ref. & & & \\
\hline$\geq 240$ & $23(74.2)$ & 75 (44.9) & 3.527 & 1.492 & 8.337 & 0.004 \\
\hline \multicolumn{7}{|l|}{ Stoma creation } \\
\hline No & $21(67.7)$ & $152(91)$ & Ref. & & & \\
\hline Yes & $10(32.3)$ & $15(9)$ & 4.825 & 1.921 & 12.122 & 0.001 \\
\hline \multicolumn{7}{|l|}{ Hypertension } \\
\hline No & $14(45.2)$ & $97(58.4)$ & Ref. & & & \\
\hline Yes & $17(54.8)$ & $69(41.6)$ & 1.707 & 0.789 & 3.693 & 0.174 \\
\hline \multicolumn{7}{|l|}{ Diabetes mellitus } \\
\hline No & $26(83.9)$ & $132(79.5)$ & Ref. & & & \\
\hline Yes & $5(16.1)$ & $34(20.5)$ & 0.747 & 0.267 & 2.088 & 0.578 \\
\hline \multicolumn{7}{|l|}{ Chronic renal failure } \\
\hline No & $27(87.1)$ & $160(96.4)$ & Ref. & & & \\
\hline Yes & $4(12.9)$ & $6(3.6)$ & 3.951 & 1.046 & 14.926 & 0.043 \\
\hline \multicolumn{7}{|c|}{ Chronic Respiratory disease } \\
\hline No & $30(96.8)$ & $162(97.6)$ & Ref. & & & \\
\hline Yes & $1(3.2)$ & $4(2.4)$ & 1.350 & 0.146 & 12.501 & 0.792 \\
\hline
\end{tabular}





Fig. 1. Cumulative incidence curves using the stage of Albumin, CRP and WBC in the ESSI or LSSI as a competing risk. 
lative incidence to differ between albumin declining group and non-declining groups. On POD\#3, the cumulative incidences of ESSI for albumin level ([Albumin Yes and Event $<7$ days] and [Albumin NO and Event $<7$ days]) were 0.043 and 0.162 , respectively. Cumulative incidence in the CRP group also tends to show a difference after POD \#4. On POD \#5, the cumulative incidences of ESSI for CRP level ([CRP Yes and Event $<7$ days] and [CRP NO and Event $<7$ days]) were 0 and 0.09 , respectively (Fig. 1). In the cause specific hazard model for occurrence of ESSI, variables with P-values lower than 0.2 (univariate analysis) were stomy formation, open surgery, operation time longer than 240 minutes, POD\#3 and \#5 low albumin levels and POD\#4 high CRP levels and stomy formation, long operation time, hypertension, chronic renal failure and POD \#3 low albumin show lower P-values with LSSI (univariate analysis) (Table 5). These variables were considered as potentially independent and employed for multivariate analysis. The risk factors associated with ESSI and LSSI after colorectal surgery by multiple regression analysis are shown in Table 6. Statistically significant risk factors for ESSI as determined by multivariate model were operation time longer than $240 \mathrm{mi}^{-}$ nutes (CHR=9.794 [95\% CI, 1.804 53.171], $\mathrm{P}<0.008$ ), and decrease in albumin levels on POD\#3 (Value $\leq 3.95$ $\mathrm{g} / \mathrm{dL}, \mathrm{CHR}=0.096$ [95\% CI, 0.025 0.369], $\mathrm{P}<0.001$ ) and elevation in CRP level on POD\#4 (Value $\geq 11.535 \mathrm{mg} / \mathrm{L}$ CHR=12.634 [95\% CI, 4.195 38.050], P=0.000). For LSSI, there were no statistically significant variables.

\section{DISCUSSION}

Surgical site infection is with a significance concern in colorectal surgery. Multiple studies show that the in-

Table 5. Univariate analysis of relative risk for surgical site infection to early SSI (ESSI) vs late SSI (LSSI)

\begin{tabular}{|c|c|c|c|c|c|c|c|c|c|}
\hline & & \multicolumn{4}{|c|}{$<7$ days $($ ESSI) } & \multicolumn{4}{|c|}{$\geq 7$ days (LSSI) } \\
\hline & & \multirow{2}{*}{$\mathrm{CHR}^{\star}$} & \multicolumn{2}{|c|}{$95 \% \mathrm{Cl}$} & \multirow{2}{*}{$P-$ value $^{\ddagger}$} & \multirow{2}{*}{$\mathrm{CHR}^{*}$} & \multicolumn{2}{|c|}{$95 \% \mathrm{Cl}$} & \multirow{2}{*}{ P-value ${ }^{\ddagger}$} \\
\hline & & & Lower & Upper & & & Lower & Upper & \\
\hline \multicolumn{2}{|l|}{ Female } & 1.139 & 0.878 & 1.139 & 0.810 & 1.104 & 0.906 & 1.104 & 0.830 \\
\hline \multicolumn{2}{|c|}{ Year $\geq 65$} & 1.132 & 0.884 & 1.132 & 0.820 & 0.711 & 0.711 & 1.407 & 0.460 \\
\hline \multicolumn{2}{|c|}{$\mathrm{BMI} \geq 25 \mathrm{~kg} / \mathrm{m}^{2}$} & 0.672 & 0.672 & 1.489 & 0.540 & 1.154 & 0.867 & 1.154 & 0.770 \\
\hline \multicolumn{2}{|c|}{ Stomy formation ${ }^{\S}$} & 3.218 & 0.311 & 3.218 & 0.048 & 2.535 & 0.394 & 2.535 & 0.065 \\
\hline \multicolumn{2}{|c|}{ Emergency operation } & 0.652 & 1.534 & 0.652 & 0.520 & 1.258 & 0.795 & 1.258 & 0.620 \\
\hline \multicolumn{2}{|c|}{ Open surgery } & 2.939 & 0.340 & 2.939 & 0.055 & 1.299 & 0.770 & 1.299 & 0.570 \\
\hline \multicolumn{2}{|c|}{ Operaitive time $\geq 240 \mathrm{~min}$} & 5.943 & 0.168 & 5.943 & 0.020 & 2.342 & 0.427 & 2.342 & 0.082 \\
\hline \multicolumn{2}{|c|}{ Hyptertension } & 1.542 & 0.649 & 1.542 & 0.430 & 1.851 & 0.540 & 1.851 & 0.180 \\
\hline \multicolumn{2}{|c|}{ Diabetes mellitus } & 0.706 & 0.706 & 1.416 & 0.650 & 1.068 & 0.937 & 1.068 & 0.910 \\
\hline \multicolumn{2}{|c|}{ Chronic renal failure } & 1.605 & 0.623 & 1.605 & 0.650 & 3.897 & 0.257 & 3.897 & 0.026 \\
\hline \multicolumn{2}{|c|}{ Chronic respiratory diseases } & 3.215 & 0.311 & 3.215 & 0.230 & $\mathrm{~N} / \mathrm{A}^{\dagger}$ & & & \\
\hline \multirow[t]{3}{*}{ POD\#1 } & CRP (mg/L) & 1.887 & 0.584 & 6.094 & 0.290 & 1.799 & 0.682 & 4.748 & 0.240 \\
\hline & WBC $(/ \mu \mathrm{L})$ & 1.131 & 0.375 & 3.414 & 0.830 & 1.065 & 0.424 & 2.679 & 0.890 \\
\hline & Albumin (g/dL) & 1.283 & 0.435 & 3.781 & 0.650 & 1.684 & 0.689 & 4.117 & 0.250 \\
\hline \multirow[t]{3}{*}{ POD\#2 } & CRP & 1.747 & 0.582 & 5.246 & 0.320 & 1.008 & 0.366 & 2.778 & 0.990 \\
\hline & WBC & 0.745 & 0.209 & 2.654 & 0.650 & 0.885 & 0.325 & 2.411 & 0.810 \\
\hline & Albumin & 0.766 & 0.261 & 2.253 & 0.630 & 1.609 & 0.638 & 4.060 & 0.310 \\
\hline \multirow[t]{3}{*}{ POD\#3 } & CRP & 1.021 & 0.340 & 3.061 & 0.970 & 1.538 & 0.630 & 3.753 & 0.340 \\
\hline & WBC & 0.737 & 0.208 & 2.608 & 0.640 & 0.873 & 0.323 & 2.359 & 0.790 \\
\hline & Albumin & 0.240 & 0.082 & 0.704 & 0.009 & 4.254 & 0.560 & 32.298 & 0.160 \\
\hline \multirow[t]{3}{*}{ POD\#4 } & CRP & 2.659 & 0.781 & 9.057 & 0.120 & 0.473 & 0.066 & 3.370 & 0.450 \\
\hline & WBC & 1.965 & 0.629 & 6.136 & 0.250 & 0.507 & 0.121 & 2.122 & 0.350 \\
\hline & Albumin & $N / A^{\dagger}$ & & & & 1.058 & 0.245 & 4.565 & 0.940 \\
\hline \multirow[t]{3}{*}{ POD\#5 } & CRP & $\mathrm{N} / \mathrm{A}^{\dagger}$ & & & & 0.724 & 0.241 & 2.171 & 0.560 \\
\hline & WBC & 0.426 & 0.096 & 1.884 & 0.260 & 1.381 & 0.554 & 3.445 & 0.490 \\
\hline & Albumin & 0.231 & 0.031 & 1.732 & 0.150 & 1.317 & 0.510 & 3.403 & 0.570 \\
\hline
\end{tabular}


Table 6. Multivariate analysis of relative risk for surgical site infection to early SSI (ESSI) vS late SSI (LSSI)

\begin{tabular}{|c|c|c|c|c|c|c|c|c|}
\hline & \multicolumn{4}{|c|}{$<7$ days $($ ESSI) } & \multicolumn{4}{|c|}{$\geq 7$ days (LSSI) } \\
\hline & \multirow{2}{*}{$\mathrm{CHR}^{*}$} & \multicolumn{2}{|c|}{$95 \% \mathrm{Cl}$} & \multirow{2}{*}{ P-value ${ }^{\dagger}$} & \multirow{2}{*}{$\mathrm{CHR}^{*}$} & \multicolumn{2}{|c|}{$95 \% \mathrm{Cl}$} & \multirow{2}{*}{ P-value ${ }^{\dagger}$} \\
\hline & & Lower & Upper & & & lower & upper & \\
\hline $\begin{array}{l}\text { Operaitive time } \geq 240 \text { min } \\
\text { POD\#3 of Albumin } \\
\text { POD\#4 of CRP }\end{array}$ & $\begin{array}{r}9.794 \\
0.096 \\
12.634\end{array}$ & $\begin{array}{l}1.804 \\
0.025 \\
4.195\end{array}$ & $\begin{array}{r}53.171 \\
0.369 \\
38.050\end{array}$ & $\begin{array}{l}0.008 \\
0.001 \\
0.000\end{array}$ & & & & \\
\hline
\end{tabular}

cidence rate of SSI after colorectal surgery is higher than other surgery types.[11,12] According to the American College of Surgeons' National Surgical Quality Improvement Program data (ACS NSQIP) widely used in United States, the SSI rates of colorectal surgery range from $9 \%$ to 14\%.[13-15] According to the Japan Nosocomial Infections Surveillance (JANIS), the incidences of SSI after colon and rectal surgery from 2008 to 2010 were $15.0 \%$ and $17.8 \%$, respectively.[16] Higher rate of SSI post colorectal surgery may be due to the inherent possibility of microbial contamination at the operation wound site.[17]

SSI rate in our study $(15.7 \%)$ is minimally higher than that of previous studies. We believe this may be due to two reasons. Firstly, the reported SSI incidence may have been underestimated in previous studies. Secondly, the actual SSI rate at our hospital may be higher than that at the others. In accordance with the first reason, 9 15\% SSI rate was reported in recent US surveys,[18,19] 10.15\% in Korean,[10] and 15.0 17.8\% in Japanese reports.[9] In accordance with the second reason, authors in this study focused on high rate of emergency operation. Compared to elective surgery, peritonitis due to perforation and stoma formation are relatively more frequent in emergency surgery, and the rate of SSI incidence is also expected to be higher. However, detailed analysis and risk-adjustment for these factors was not performed. For a more meaningful comparisons of SSI rates across each hospital setting, calibration is required for each hospital's patient population as is performed by the National Healthcare Safety Network (NHSN) risk-adjusted measurement system in the United States.

In accordance with the antibiotic guideline for SSI pre- vention, our institute has a standard principle of administering second-generation cephalosporin IV antibiotics twice, at 30 minutes pre-operation and at post operation. However, in cases requiring emergency surgery, antibiotics are used for treatment of peritonitis or sepsis before operation, and antibiotic treatment should be continued for a longer period after surgery. Compared to previous studies, this institute conducts relatively more emergency operations, and this may have affected the outcome of this study; however, this study did not control for these differences.

In this study, we classified SSI into two groups; before POD\#7 (Early SSI) and after and POD\#7 (Late SSI). 'POD\#7' was based on the average post-operative admission of a target patient population (6.2 days). This may be slightly higher than other hospitals (also when compared to our recent data), considering that the emergency operation rate is slightly higher in our hospital, however no detailed analysis focused on this factor has been performed.

We examined the possibility of employing albumin, WBC and CRP as tools to predict the occurrence of SSI by analyzing the correlation between postoperative albumin, WBC and CRP levels after surgery with occurrence of SSI using multiple statistical analysis methodologies. According to statistical results, ESSI could be reliably predicted when albumin level decreased on POD\#3 $(\leq 3.95)$ and CRP level was elevated on POD $4(\geq 11.535 \mathrm{mg} / \mathrm{L})$.

Malnutrition has an adverse effect on outcomes in surgical patients.[20] Albumin is most commonly used as an indicator of the nutritional status of a patient and is a negative acute-phase protein that is downregulated in re- 
sponse to acute illness or stress.[21] A recent study shows that hypoalbuminemia is an independent risk factor for the development of SSI following gastro-intestinal surgery. It shows that albumin $<30 \mathrm{mg} / \mathrm{dL}$ was associated with an increased rate of SSI.[22]

C-reactive protein (CRP) and white blood cells (WBC) are known as biologic markers of postoperative infection. [23-25] They have limited sensitivity and are good predictors of SSI. In a recent study, postoperative CRP level at 48 hours was useful in predicting organ-space surgical site infection after colorectal surgery.[26] In a similar study, elevated CRP levels at $2^{\text {nd }}$ and $4^{\text {th }}$ post-operative day (POD) were considered as predictors of anastomotic leak and postoperative complication after colorectal surgery. Multivariate analysis suggested that CRP level $>125 \mathrm{mg} / \mathrm{L}$ at 4 th POD was a significant predictor for anastomotic leak (Odd ratio [OR] 18.15) and septic complication (OR 14.27).[27]

We carefully recommend that clinicians measure albumin level as an indicator of nutritional status and CRP level as an inflammation marker more frequently for earlier detection of SSI. Although studies should be conducted on cohorts with more homogeneous and large numbers of patient, this study is meaningful in that it raised the necessity of monitoring nutritional status including serum albumin level.

In addition to albumin and CRP levels, univariate and multivariate analysis showed that longer operation time, $\mathrm{CRF}$ and stoma formation were other significant risk factors of SSI.

Limitations of this study include its small sample size, which was not adequate to analyze all of the risk factors of SSI. Additionally, all of the operations were conducted in a single hospital and by a single colorectal team, thereby limiting any variation that may occur in different facilities. Most importantly, a selection bias may exist as the study data was collected retrospectively. This may limit the study to identify all of the risk factors associated with SSI.

And we did not investigate the degree of infection according to SSI classification. Although we assessed wound infection through thorough surveillance, this would be another limitation. Therefore, further research is needed in the future.

The biggest limitation is that because this study was based entirely on the national SSI survey report and chart records, we could not investigate other factors that could assess nutritional status of patients except for the albumin levels and overweight. We plan to increase the number of patients participating in the study, and to study other nutritional indicators.

\section{REFERENCES}

1. Waltz PK, Zuckerbraun BS. Surgical site infections and associated operative characteristics. Surg Infect (Larchmt) 2017;18: 447-50.

2. Anderson DJ, Podgorny K, Berríos-Torres SI, Bratzler DW, Dellinger EP, Greene L, et al. Strategies to prevent surgical site infections in acute care hospitals: 2014 update. Infect Control Hosp Epidemiol 2014;35:605-27.

3. Zimlichman E, Henderson D, Tamir O, Franz C, Song P, Yamin CK, et al. Health care-associated infections: a meta-analysis of costs and financial impact on the US health care system. JAMA Intern Med 2013;173:2039-46.

4. Anderson DJ, Kaye KS, Chen LF, Schmader KE, Choi Y, Sloane $R$, et al. Clinical and financial outcomes due to methicillin resistant Staphylococcus aureus surgical site infection: a multi-center matched outcomes study. PLoS One 2009;4:e8305.

5. Silvestri M, Dobrinja C, Scomersi S, Giudici F, Turoldo A, Princic E, et al. Modifiable and non-modifiable risk factors for surgical site infection after colorectal surgery: a single-center experience. Surg Today 2018;48:338-45.

6. Lee KY, Coleman K, Paech D, Norris S, Tan JT. The epidemiology and cost of surgical site infections in Korea: a systematic review. J Korean Surg Soc 2011;81:295-307.

7. Kwak YG, Choi JY, Yoo HM, Lee SO, Kim HB, Han SH, et al. Validation of the Korean National Healthcare-associated Infections Surveillance System (KONIS): an intensive care unit module report. J Hosp Infect 2017;96:377-84.

8. Choi HJ, Adiyani L, Sung J, Choi JY, Kim HB, Kim YK, et al. Five-year decreased incidence of surgical site infections following gastrectomy and prosthetic joint replacement surgery through active surveillance by the Korean Nosocomial Infection Surveillance System. J Hosp Infect 2016;93:339-46.

9. Kwak YG, Lee SO, Kim HY, Kim YK, Park ES, Jin HY, et al. Risk factors for device-associated infection related to organisational characteristics of intensive care units: findings from the Korean Nosocomial Infections Surveillance System. J Hosp Infect 2010;75:195-9.

10. Park SJ, Lee KY, Park JW, Lee JG, Choi HJ, Chun HK, et al. A preliminary study for the development of indices and the current state of surgical site infections (SSIs) in Korea: the Korean Surgical Site Infection Surveillance (KOSSIS) program. Ann Surg Treat Res 2015;88:119-25.

11. Petrosillo N, Drapeau CM, Nicastri E, Martini L, Ippolito G, Moro ML, et al. Surgical site infections in Italian hospitals: a prospective multicenter study. BMC Infect Dis 2008;8:34.

12. Wick EC, Vogel JD, Church JM, Remzi F, Fazio VW. Surgical site infections in a "high outlier" institution: are colorectal surgeons to blame? Dis Colon Rectum 2009;52:374-9. 
13. Cima R, Dankbar E, Lovely J, Pendlimari R, Aronhalt K, Nehring $S$, et al. Colorectal surgery surgical site infection reduction program: a national surgical quality improvement program--driven multidisciplinary single-institution experience. J Am Coll Surg 2013;216:23-33.

14. Kohut AY, Liu JJ, Stein DE, Sensenig R, Poggio JL. Patientspecific risk factors are predictive for postoperative adverse events in colorectal surgery: an American College of Surgeons National Surgical Quality Improvement Program-based analysis. Am J Surg 2015;209:219-29.

15. Kiran RP, El-Gazzaz GH, Vogel JD, Remzi FH. Laparoscopic approach significantly reduces surgical site infections after colorectal surgery: data from national surgical quality improvement program. J Am Coll Surg 2010;211:232-8.

16. Morikane K, Honda H, Yamagishi T, Suzuki S, Aminaka M. Factors associated with surgical site infection in colorectal surgery: the Japan nosocomial infections surveillance. Infect Control Hosp Epidemiol 2014;35:660-6.

17. Watanabe M, Suzuki H, Nomura S, Maejima K, Chihara N, Komine $\mathrm{O}$, et al. Risk factors for surgical site infection in emergency colorectal surgery: a retrospective analysis. Surg Infect (Larchmt) 2014;15:256-61.

18. Paulson EC, Thompson E, Mahmoud N. Surgical site infection and colorectal surgical procedures: a prospective analysis of risk factors. Surg Infect (Larchmt) 2017;18:520-6.

19. Aimaq R, Akopian G, Kaufman HS. Surgical site infection rates in laparoscopic versus open colorectal surgery. Am Surg 2011;77:1290-4.

20. Inoue Y, Miki C, Kusunoki M. Nutritional status and cytokine-related protein breakdown in elderly patients with gastrointestinal malignancies. J Surg Oncol 2004;86:91-8.
21. Sung J, Bochicchio GV, Joshi M, Bochicchio K, Costas A, Tracy $\mathrm{K}$, et al. Admission serum albumin is predicitve of outcome in critically ill trauma patients. Am Surg 2004;70:1099-102.

22. Hennessey DB, Burke JP, Ni-Dhonochu T, Shields C, Winter DC, Mealy K. Preoperative hypoalbuminemia is an independent risk factor for the development of surgical site infection following gastrointestinal surgery: a multi-institutional study. Ann Surg 2010;252:325-9.

23. Goulart A, Ferreira C, Estrada A, Nogueira F, Martins S, Mesquita-Rodrigues A, et al. Early inflammatory biomarkers as predictive factors for freedom from infection after colorectal cancer surgery: a prospective cohort study. Surg Infect (Larchmt) 2018;19:446-50.

24. Adamina M, Steffen T, Tarantino I, Beutner U, Schmied BM, Warschkow R. Meta-analysis of the predictive value of C-reactive protein for infectious complications in abdominal surgery. Br J Surg 2015;102:590-8.

25. Bilgin IA, Hatipoglu E, Aghayeva A, Arikan AE, Incir S, Mamal Torun $M$, et al. Predicting value of serum procalcitonin, C-reactive protein, drain fluid culture, drain fluid interleukin-6, and tumor necrosis factor- $\alpha$ levels in anastomotic leakage after rectal resection. Surg Infect (Larchmt) 2017;18:350-6.

26. Juvany M, Guirao X, Oliva JC, Badía Pérez JM. Role of combined post-operative venous lactate and 48 hours $\mathrm{C}$-reactive protein values on the etiology and predictive capacity of organ-space surgical site infection after elective colorectal operation. Surg Infect (Larchmt) 2017;18:311-8.

27. Ortega-Deballon P, Radais F, Facy O, d'Athis P, Masson D, Charles PE, et al. C-reactive protein is an early predictor of septic complications after elective colorectal surgery. World J Surg 2010;34:808-14. 